\title{
Non-Linear Predictability of UK Stock Market Returns
}

\author{
David G McMillan \\ Department of Accountancy and Finance \\ University of Aberdeen
}

September 2002

\begin{abstract}
$\underline{\text { Abstract }}$
Linear predictability of stock market returns has been widely reported. However, recently developed theoretical research has suggested that due to the interaction of noise and arbitrage traders, stock returns are inherently non-linear, whereby market dynamics differ between small and large returns. This paper examines whether an exponential smooth transition threshold model, which is capable of capturing this non-linear behaviour, can provide a better characterisation of UK stock market returns than either a linear model or an alternate non-linear model. Results of both insample and out-of-sample specification tests support the exponential smooth transition threshold model and hence the belief that investor behaviour does differ between large and small return.
\end{abstract}

Keywords: Stock Market Returns Predictability, Smooth Transition Threshold Model, Non-Linear JEL: C22, G12 
e-mail: d.mcmillan@abdn.ac.uk 


\section{Introduction.}

A rapidly growing body of evidence suggests that stock market returns can be predicted by a range of financial and macroeconomic variables and that this conclusion holds across a variety stock markets and time horizons. More specifically, cross-sectional studies of US equity returns have reported that fundamental variables, such as earnings yield, cash flow yield, book-to-market ratio and size, have predictive power (e.g. Basu, 1977; Fama and French, 1992; Lakonishok, Shliefer and Vishny, 1994). In time series analysis Fama and French (1993) identify three common risk factors, namely, market risk, size and book-to-market, which are able to explain average stock returns. While a series of studies report predictive power in a variety of other variable, including interest rates, inflation and output (e.g. Keim and Stambaugh, 1986; Campbell, 1987; French, Schwert and Stambaugh, 1987; Fama and French, 1989, Balvers, Cosimano and McDoanld, 1990; Breen, Glosten and Jagannathan, 1990; Cochrane, 1991; Campbell and Hamao, 1992; Ferson and Harvey, 1993; Glosten, Jagannathan and Runkle, 1993; and Pesaran and Timmerman, 1995, 2000).

Whilst early studies suggested that such predictability was inconsistent with market efficiency and reflected inherent irrational investor behaviour which may be exploited in trading strategies (Cutler, Poterba and Summers, 1989), predictability can also be viewed with respect to arbitrage pricing models (Ross, 1976). Specifically, whilst arbitrage pricing theory does not imply predictability as it derives stock returns as a linear function of contemporaneous factors, so-called conditional asset pricing models attempt to explain asset returns using available information. Moreover, Ferson and Harvey (1991) show that such asset returns predictability does not arise due to market inefficiency but from predictability in the variables which form the information set. That is variables such as output and interest rates which in part determine stock returns are themselves predictable. Whilst an alternative rationale for the stock returns 
predictability is provided by time-variation in required rates of return (Cochrane, 1999, 2001).

However, whilst the vast majority of the extant work examines stock return predictability in a linear regression framework, there is increasing evidence that asset returns may be better characterised by a model which allows for non-linear behaviour (Abhyankar, Copeland and Wong, 1997 provide a summary of recent evidence of non-linearitydependence in asset returns). Recent exceptions to this include the work of Leung, Daouk and Chen (2000) who use neural network methods to examine the predictability of international stock returns, Perez-Quiros and Timmermann (2000) who employ a Markov switching model to predict returns in large and small US firms, and McMillan (2001) who examines threshold predictability of US index returns.

Moreover, there is increasing theoretical recognition that financial markets may be characterised by non-linear behaviour resulting from the interaction between informed and noise traders and the presence of market frictions and transaction costs, which may cover a broad range of costs such as the bid-ask spread, short-selling and borrowing constraints and other transactions costs, such that a band of price movements occur around the equilibrium price where arbitrageurs only actively trade when deviations from equilibrium become sufficiently large. Consequently, the dynamic behaviour of returns will differ according to the size of the deviation in prices from equilibrium, giving rise to asymmetric dynamics for returns of differing size (Dumas, 1992, 1994; Krägler and Krugler, 1993; Secru et. al., 1995; Obstfeld and Taylor, 1997; Martens, Kofman and Vorst, 1998; Coakley and Furtes, 1998; Schleifer, 2000).

To this end, using UK stock market returns and a variety of financial and macroeconomic variables, we consider smooth-transition threshold models (STR, Chan and Tong, 1986; Teräsvirta and Anderson, 1992; Granger and Teräsvirta, 1993; Teräsvirta, 1994) which are capable of capturing behaviour consistent with both noise trader models and more general nonlinear behaviour perhaps arising from the general state of the market (i.e. whether the market is 
rising or falling). More specifically, smooth-transition models allow the possibility of gradual movement between regimes, and are able to capture two types of asymmetric adjustment. First, the parameters of the model change depending on whether retums take a value above or below the threshold parameter, i.e. the direction of dis-equilibrium; and second, the parameters of the model change depending on the whether returns term takes a large or small value, i.e. the size of dis-equilibrium. This latter transition function which suggest different dynamics between the middle and outer regimes is consistent with the theoretical models discussed in the above noted papers, that trader behaviour alters once prices have moved sufficiently away from equilibrium.

The remainder of this paper is organised as follows, Section 2 provide a brief overview of the theoretical literature concerning the potential for threshold non-linearities in financial market returns data. Section 3 outlines the threshold models. Section 4 presents the empirical results and model specification and evaluation tests. Section 5 provides a summary and concludes our findings.

\section{Theoretical Background for Non-Linear Dynamics.}

As noted in the introduction, an issue which has received much attention in the empirical finance literature of late, and which offers an appealing explanation for asymmetries in market returns, is related to the interaction of informed traders and 'noise traders'. trading means that profitable opportunities will inevitably arise for privately informed and arbitrage traders. In early recognition of the potential non-linear consequences of such interaction, Cootner (1962) noted that the activities of noise traders will cause prices to hit upper or lower 'reflecting barriers' around equilibrium, and thus trigger arbitrage activities by informed traders which push prices back to equilibrium. Cootner argued further that the position of such barriers is likely to depend on the size of market frictions such as transactions costs, giving rise 
to a band of price movements around the equilibrium price. Thus, informed traders only actively trade when deviations from equilibrium are sufficiently large to make arbitrage trade profitable (He and Modest, 1995).

A related explanation for the possible existence of nonlinear adjustment, originally advocated in the context of foreign exchange markets, holds that small deviations from fundamental equilibrium may be considered relatively unimportant by both the market and policy makers. Consequently, only limited significance will be attached to market forces which are not governed by economic fundamentals, such as trading behaviour based on technical analysis and chartism. ${ }^{2}$ However, as the market price becomes increasingly misaligned, pressure from both the market and policy makers could be expected to return the exchange rate to its fundamental equilibrium value. Indeed, a series of rec ent papers ex amining both real and nominal exchange rates has reported affirmatoryevidence of threshold effects (Obstfeld and Taylor, 1997; Martens, Kofman and Vorst, 1998; Coakley and Fuertes, 1998). More formal models of international goods market arbitrage examined by Dumas $(1992,1994)$ and Sercu et. al. (1995) have similarly suggested that the presence of transactions cost which result in small imbalances being left uncorrected may impart nonlinear adjustment to equilibrium due to nonlinear factors affecting the costs of arbitrage, such that the speed of reversion to equilibrium increases with the size of the deviation.

The above models rely on transactions costs to limit arbitrage around fundamental equilibrium and thus create bands of inactivity about the equilibrium price which must be breached before arbitrage takes place, such that small and large deviation from equilibrium are characterised by different dynamics. An alternative explanation put forward by Shleifer (2000) argues that, even in the absence of transaction costs, noise trading can produce limits to arbi trage such that large deviations from equilibrium are required before arbitrage occurs. This Shleifer 
ascribes to 'mis-price deepening'. That is, where noise traders' beliefs become even more extreme before they are subject to correction, providing an additional source of risk to be faced by arbitrageurs, particularly if they are subject to a short horizon. ${ }^{3}$ Consequently, the risk of a further movement of noise traders' opinion away from the fundamental equilibrium must be borne in mind by arbitrageurs and may limit their willingness to take a contrary position to noise traders. For example, if noise traders are pessimistic today about an asset and have thereby driven its price down, an arbitrageur buying this asset needs to recognise that noise traders might become even more pessimistic and drive the price down even further in the near future; if the arbitrageur has to liquidate their position before the price recovers, they will suffer a loss, and fear of this loss could limit the original arbitrage position. Conversely, an arbitrageur selling an asset short when bullish noise traders have driven its price up needs to be aware that noise traders might become even more bullish tomorrow, and so must take a position that accounts for the risk of a further price rise when they have to buy back the asset.

\section{Smooth-Transition Threshold Models.}

In order to examine for a potential non-linear relationship between UK index returns and both financial and macroeconomic variables we consider the class of smooth-transition threshold models. The smooth transition models (see Chan and Tong, 1986; Teräsvirta and Anderson, 1992; Granger and Teräsvirta, 1993; Teräsvirta, 1994) allow for smooth transition between regimes of behaviour, which is theoretically more appealing over the simple threshold models which impose an abrupt switch in parameter values because only if all traders act simultaneously will this be the observed outcome, for a market of many traders acting at slightly different times a smooth transition model is more appropriate. Additionally, the STR model allows different types of market behaviour depending on the nature of the transition function. In particular the 
logistic function allows differing behaviour depending on whether returns are positive or negative, while the exponential function allows differing behaviour to occur for large and small returns regardless of sign. The former function is motivated by considerations of the general state of the market, while the latter function maybe motivated by considerations of market frictions, such as transactions costs or noise trader risk, which create a band of price movements around the equilibrium price, with arbitrageurs only actively trading when deviations from equilibrium are sufficiently large, as discussed in Section $2 .^{6}$ The threshold model can be given by:

$$
r_{t}=\pi_{0}+\Sigma_{i=1}^{p} \pi_{i} z_{t-i}+\left(\theta_{0}+\Sigma_{i=1}^{p} \theta_{i} z_{t-i}\right) F\left(r_{t-d}\right)+\varepsilon_{t}
$$

where $r_{t}$ is the return, $z_{t-i}$ represents the 'other variables' and $F\left(r_{t-d}\right)$ is the transition function, where $r_{t-d}$ is the transition variable. As already stated, two transition functions are considered. The logistic function is given as follows, with the full model thus referred to as a Logistic STR (or LSTR) model:

$$
F\left(r_{t-d}\right)=\left(1+\exp \left(-\gamma\left(r_{t-d}-c\right)\right)\right)^{-1}, \quad \gamma>0
$$

which allows a smooth transition between the differing dynamics of positive and negative returns, where $d$ is the delay parameter, the smoothing parameter, and the transition parameter. This function allows the parameters to change monotonically with $\boldsymbol{r}_{\boldsymbol{t}-\boldsymbol{d}}$. As, , $F\left(\boldsymbol{r}_{\boldsymbol{t}-\boldsymbol{d}}\right)$ becomes a Heaviside function: $F\left(\boldsymbol{r}_{\boldsymbol{t}-\boldsymbol{d}}\right)=0, \boldsymbol{r}_{\boldsymbol{t}-\boldsymbol{d}} \quad c, F\left(\boldsymbol{r}_{\boldsymbol{t}-\boldsymbol{d}}\right)=1, \boldsymbol{r}_{\boldsymbol{t}-\boldsymbol{d}} \quad c$, and (1) reduces to Threshold model (Chan, 1993). As $\quad$, (1) becomes a linear model of order $p$.

The second transition function considered is exponential, with the resulting model referred to as the Exponential STR (or ESTR) model:

$$
F\left(r_{t-d}\right)=1-\exp \left(-\gamma\left(r_{t-d}-c\right)^{2}\right), \quad \gamma>0
$$

Whereby the parameters in (3) change symmetrically about $c$ with $r_{t-d}$. This model implies that 
the dynamics of the middle ground differ from those of the larger returns. The ESTR model is a generalisation of the regular exponential autoregressive (EAR) model of Haggan and Ozaki (1981), where $\theta_{o}==0$, this generalisation making the EAR model location invariant. The ESTR model thus identifies differing behaviour resulting from large and small trades.

Estimation of STR models is bynon-linear least squares. ${ }^{7}$ A particular issue in estimating smooth transition models concerns the smoothing parameter, estimation of which has in practice been problematic. In the LSTR model, a large results in a steep slope of the transition function at $c$, thus a large number of observations in the neighbourhood of $c$ are required to estimate accurately. Additionally, a result of this is that convergence of may be slow, with relatively large changes in having only a minor effect upon the shape of the transition function. A solution to this, suggested by Teräsvirta and Anderson (1992), Granger and Teräsvirta (1993) and Teräsvirta (1994) is to scale the smoothing parameter, , by the standard deviation of the transition variable, and similarly in the ESTR model to scale by the variance of the transition variable. Thus, the LSTR and ESTR models become respectively: ESTARX models become respectively:

$$
\begin{aligned}
& F\left(x_{t-d}\right)=\left(1+\exp \left(-\gamma\left(x_{t-d}-c\right) / \sigma\left(x_{t-d}\right)\right)\right)^{-1} \\
& F\left(x_{t-d}\right)=1-\exp \left(-\gamma\left(x_{t-d}-c\right)^{2} / \sigma^{2}\left(x_{t-d}\right)\right)
\end{aligned}
$$

\section{Data and Empirical Results.}

Quarterly UK FT-ALL stock market index data is analysed over the period 1970:1 to 1995:4, with the sample period from 1996:1 to 2001:4 being used in an out-of-sample forecasting exercise. The following quarterly financial and macroeconomic data are used to attempt to predict the returns process, the dividend yield, the 3-month Treasury bill, the 10-year Treasurybond, unemployment, industrial production, private consumption, consumer price index and money supply M1. ${ }^{8}$ All data was tested for the presence of unit roots using the test Augment 
Dickey-Fuller tests. The results suggest a single unit root in each series, except the stock market index returns series, where a unit root is present in the levels (price) data, thus to ensure stationarity all relevant data is differenced. ${ }^{9}$

We begin the examination of the data by using a standard linear regression model of the following form:

$$
x_{t}=a_{0}+\sum_{i=1}^{m} a_{i} z_{t-i}+\varepsilon_{t}
$$

where $x_{t}$ represents the stock market returns and $z_{t}$ the financial and macroeconomic series. Initially we consider a lag length of four, and estimate the model over the period 1975:1 to 1995:4, retaining the remaining observations to conduct an out-of-sample forecasting exercise. Lags are eliminated on the basis of individual significance test, while joint significance tests are performed on the final specific model, information criteria such as the AIC and BIC were also used to inform appropriate lag lengths decisions. Table 1 presents the estimated results for equation (4). The results show that only the second lag of the dividend yield and industrial production and the first lag of the 3-month Treasury bill have significant predictive power. More specifically, a positive relationship exists between the dividend yield and equity returns, which could be associated with a previous fall in prices (perhaps due to a rise in the discount rate) leading to both higher returns and yields, or a rise in dividends; whilst a negative relationship exists between index returns and yields on treasury bills and growth in industrial production. This former relationship could be rationalised whereby investors have noted a previous rise in interest rates now expected a future fall in rates and hence current equity prices rise and future returns fall, while the latter is rationalised such that a rise in output would lead to increased future cash flow and dividends thus raising current prices while future returns fall. Finally, the constant term is significant and positive indicating upward drift in returns. ${ }^{10}$

The coefficient estimates of the two non-linear threshold models are also presented in 
Table 1. In the LSTR model all lagged parameters appears in the lower (negative returns) regime, whilst no exogenous parameters are significant in the upper regime. The sign of the parameters, including the constant, remains the same as in the linear case. The estimated transition parameter, $c$, marks the half-way point between the two regimes, that is where $F\left(r_{t-d}\right)=$ $1 / 2$ as $r_{t-1}-c=0$, and is estimated to be approximately 0.02 . The speed of transition between regimes, which is captured by the parameter , is found to be quick and indicates possible Heaviside threshold behaviour as opposed to a smooth transition. Confirmation of this can be seen in the upper panel of Figure 1 which plots the transition function.

The coefficient estimates for the ESTR model are reported in the final column of Table 1. Of immediate note is that in the middle regime, which corresponds to small returns where $F\left(r_{t-d}\right) \simeq 0$, which arises as $\left(r_{t-d}-c\right) \rightarrow 0$, returns are characterised by a random walk with positive drift. Whilst the predictability of returns occurs in the outer regimes (large returns), corresponding to $F\left(r_{t-d}\right) \neq 0$ as $\left(r_{t-d}-c\right) \rightarrow \infty$, where again the coefficients have the same sign as in the linear case. The estimated value of the threshold parameter, $c$, suggests that the central regime characterises returns that are less than $4 \%$. Transition between regimes is dictated by the estimated transition function, which is portrayed in the lower panel in Figure 1. The minimum of the function corresponds with the threshold parameter, its width in the neighbourhood of $c$ determines the range of the central regime, whilst its steepness (symmetric about $c$ ) determines the speed of transition between the centre and outer regimes. The estimated transition parameter value of 0.53 is significant at the $10 \%$ level and suggests only a moderate speed of transition between regimes, and therefore a tendency for returns to sojourn in the centre regime. Moreover, the results for the ESTR model are consistent with the noise traders arguments presented in section 2. That is, only when returns become sufficiently large (deviate from fundamental equilibrium) do arbitrageurs act in a consistent manner, to drive prices back to equilibrium, and 
hence returns in this regime become predictable. When returns are small they are unpredictable as no single group of traders acts to push prices in a particular direction instead prices fluctuation as traders take different views of the market.

Table 2 presents a series of specification tests for the estimated models, as well as a residual test which shows no evidence of remaining serial correlation for any model. The specification tests include standard measures of in-sample fit and out-of-sample forecasting performance, as well as BDS statistics, which test for iid residuals and thus provide a general test for remaining non-linearity ofunspecified form. ${ }^{11}$ These tests support the ESTR model over both the linear and LSTR models on all criterion, whilst the performance of these latter two models is similar. More specifically regarding the in-sample measures, the ESTR model obtains the highest $R^{2}$, lowest estimated variance, highest log-likelihood function, lowest AIC and BIC information criteria and lowest in-sample root mean squared error (RMSE). Further, BDS statistics are significant for the linear model suggesting remaining (non-linear) structure in the residuals, thus supporting estimation of the non-linear models. Additionally, BDS statistics for the LSTR model also suggest non-iiid residuals, whilst the statistics for the ESTR model are insignificant suggesting the ESTR model captures all structure within the data. Regarding the out-of-sample measure again the ESTR model obtains the lowest RMSE.

To compliment this latter analysis and to provide a evaluation method which may be of more interest to practitioners, we examine the relative performance of trading strategies based upon the estimated models. The trading strategy assumes that at the beginning of each period (quarter) investors make a decision whether to invest in the stock index fund, where the price of the fund is directly proportional to the index level, or invest in Treasury-bills. Further, it is assumed that the investment is 'locked-in' for that period. The decision criteria as to whether to purchase the index fund is based on the forecasted returns, specifically, if the forecasted return 
is greater than zero then purchase the index fund, if not then purchase the Treasury-bill. Using this trading strategy we can compute the excess return over all the out-of-sample forecast period. The results from this procedure show a return to the linear and LSTR model of $52 \%$, while a return to the ESTR model of 54\%, thus, marginally, supporting the ESTR model.

In sum, thus, these results support the noise trader models described in Section 2 where arbitrageurs are not able to instantaneously engage in trade when the stock price deviates from its fundamental value. Instead, as a result of transactions costs and noise trader risk, a band develops around the equilibrium price, through which the market price must pass before arbitrageurs actively engage in trade. Traders, thus, are more interested in size of price movements than the sign of price movements.

\section{Summary and Conclusion.}

Linear predictability of stock market returns has been widely reported, with the belief that such predictability arises due to time-variation in required returns and the presence of noise traders. However, several theoretical models suggest that the interaction of noise and arbitrage traders could result in non-linear dynamics such that the price deviation from its fundamental equilibrium has to be sufficiently large before arbitrageurs actively engage in market. That is, small and large returns may exhibit differing dynamics as the existence of transaction costs or noise trader risk imparts bands of inactivity around the fundamental price. This paper has presented evidence of a non-linear relationship between UK stock market returns and publically available macroeconomic and financial data.

Specifically, a linear model is initially estimated with lags of the dividend yield, Trea surybill and industrial production providing some predictive power for FT-ALL returns. A non-linear model which is able to capture the behaviour implied by the theoretical models of 'noise traders' 
is estimated, as well as a model intended to capture non-linearities arising from the general state of the market, namely, exponential and logistic smooth transition threshold models respectively. The results show that the exponential smooth transitions threshold model improves both the insample fit and out-of-sample forecast of the data over both the linear and logistic smooth transitions threshold alternatives. Thus, these results support the noise trader models where a band of inactivity around the equilibrium price develops for which arbitrageurs required the price exceed before actively trading. It remains an avenue for further research to examine other market settings to determine whether this conclusion holds across a variety of market settings, including emerging markets. 
Table 1. Conditional Mean Model Estimates.

\begin{tabular}{|c|c|c|c|}
\hline & Linear & LSTR & ESTR \\
\hline 0 & $\begin{array}{c}0.0432 \\
(0.0084)\end{array}$ & $\begin{array}{c}0.0572 \\
(0.0133)\end{array}$ & $\begin{array}{c}0.0239 \\
(0.0114)\end{array}$ \\
\hline $\operatorname{Divy}(-2)$ & $\begin{array}{c}0.3123 \\
(0.1270)\end{array}$ & $\begin{array}{c}0.3001 \\
(0.1208)\end{array}$ & - \\
\hline Tbill(-1) & $\begin{array}{l}-0.1419 \\
(0.0500)\end{array}$ & $\begin{array}{l}-0.1632 \\
(0.0615)\end{array}$ & - \\
\hline $\operatorname{IP}(-2)$ & $\begin{array}{c}-1.4242 \\
(0.4604)\end{array}$ & $\begin{array}{l}-1.9209 \\
(0.4891)\end{array}$ & - \\
\hline 0 & - & $\begin{array}{l}-0.0225 \\
(0.0173)\end{array}$ & $\begin{array}{c}0.0464 \\
(0.0373)\end{array}$ \\
\hline $\operatorname{Divy}(-2)$ & - & - & $\begin{array}{c}0.5078 \\
(0.1767)\end{array}$ \\
\hline Tbill(-1) & - & - & $\begin{array}{c}-0.2674 \\
(0.2016)\end{array}$ \\
\hline \multirow[t]{2}{*}{$\operatorname{IP}(-2)$} & - & - & $\begin{array}{c}-3.1693 \\
(1.3422)\end{array}$ \\
\hline & - & $\begin{array}{c}96.3637 \\
(321.555)\end{array}$ & $\begin{array}{c}0.5265 \\
(0.3087)\end{array}$ \\
\hline$c$ & - & $\begin{array}{c}0.0205 \\
(0.0048)\end{array}$ & $\begin{array}{c}0.0362 \\
(0.0141)\end{array}$ \\
\hline
\end{tabular}

Notes: for equation specification see section 2. Numbers in parentheses are heteroscedasticity corrected standard errors. 


\begin{tabular}{|c|c|c|c|}
\hline & Linear & LSTR & ESTR \\
\hline Mean & 0.00 & 0.00 & 0.00 \\
\hline Std Dev & 0.072 & 0.071 & 0.066 \\
\hline Q4 & 4.01 & 6.23 & 1.37 \\
\hline Q12 & 9.75 & 10.96 & 9.19 \\
\hline $\mathrm{R}^{2}$ & 0.27 & 0.28 & $0.38^{*}$ \\
\hline$\hat{\sigma}$ & 0.43 & 0.42 & $0.36^{*}$ \\
\hline $\log L$ & 102.81 & 103.12 & $109.68 *$ \\
\hline $\mathrm{AIC}$ & -2.3525 & -2.2886 & $-2.4447 *$ \\
\hline $\mathrm{BIC}$ & -2.2368 & -2.0860 & $-2.2421 *$ \\
\hline $\operatorname{BDS}(2,1)$ & $\begin{array}{c}0.0203 \\
(0.06)\end{array}$ & $\begin{array}{c}0.0263 \\
(0.01)\end{array}$ & $\begin{array}{c}0.0118 \\
(0.15)\end{array}$ \\
\hline $\operatorname{BDS}(3,1)$ & $\begin{array}{c}0.0249 \\
(0.01)\end{array}$ & $\begin{array}{c}0.0256 \\
(0.01)\end{array}$ & $\begin{array}{c}0.0134 \\
(0.07)\end{array}$ \\
\hline $\operatorname{BDS}(4,1)$ & $\begin{array}{c}0.0216 \\
(0.01)\end{array}$ & $\begin{array}{c}0.0230 \\
(0.00)\end{array}$ & $\begin{array}{c}0.0081 \\
(0.18)\end{array}$ \\
\hline RMS E - in sample & 0.0712 & 0.0709 & $0.0656^{*}$ \\
\hline RMS E - out samp le & 0.0395 & 0.0417 & $0.0378^{*}$ \\
\hline \multicolumn{4}{|c|}{$\begin{array}{l}\text { Notes: asterisk denotes the preferred model on each specification } \\
\text { test. }\end{array}$} \\
\hline
\end{tabular}




\section{References:}

Abhyankar, A. Copeland, L.S. and Wong, W. (1997), 'Uncovering Nonlinear Structure in RealTime Stock Market indices', Journal of Business and Economic Statistics, Vol. 15, pp. 1-14.

Balvers, R.J. Cosimano, R.F. and McDonald, B. (1990), 'Predicting Stock Returns in an Efficient Market', Journal of Finance, Vol. 45, pp. 1109-1128.

Basu, S. (1997). 'The Investment Performance of Common Stocks in Relation to their PriceEarnings Ratios: A Test of the Efficient Market Hypothesis', Journal of Finance, Vol. 32, pp. 663-682.

Biasis, B. and Hillion, P. (1994). 'Insider and Liquidity Trading in Stock and Options Markets', Review of Financial Studies, Vol. 7, pp. 743-780.

Black, F. (1986). 'Noise', Journal of Finance, Vol. 41, pp. 529-543.

Breen, W. Glosten, L.R. and Jagannathan, R. (1990), 'Predictable Variations in Stock Index Returns', Journal of Finance, Vol. 44, pp. 1177-1189.

Brock, W., Dechert, W. D., Scheinkman, J. and LeBaron, B (1996), 'A Test for Independence Based on the Correlation Dimension', Econometric Reviews, Vol. 15, pp. 197-235.

Brock, W., Hsieh, D. A. and LeBaron, B (1991), Nonlinear Dynamics, Chaos and Instability: Statistical Theory and Economic Evidence. Massachusetts: MIT Press.

Campbell, J.Y.(1987), 'Stock Returns and the Term Structure' Journal of Financial Economics, Vol. 18, pp. 3-37.

Campbell, J.Y. and Hamao, Y. (1992), 'Predictable Stock Returns in the United States and Japan: A Study of Long-Term Capital Integration', Journal of Finance, Vol. 47, pp. 43-67.

Chan, K. and Tong, H. (1986), 'On Estimating Thresholds in Autoregressive Models', Journal of Time Series Analysis, Vol. 7, pp. 179-194.

Coakley, J. and Fuertes, A. M. (1998). Nonlinearities in Excess Foreign Exchange Returns. Birbeck College Discussion Paper 5/98.

Cochrane, J.H. (1991), ' Production-Based Asset Pricing and the Link between Stock Returns and Economic Fluctuations', Journal of Finance, Vol, 46, pp. 209-238.

Cochrane, J H (1999) New Facts in Finance, Economic Perspectives Federal Reserve Bank of Chicago, 23, 36-58.

Cochrane, J H (2001) Asset Pricing, Princeton University Press: Princeton.

Cootner, P. H. (1962). Stock Prices: Random versus Systematic Changes. Industrial Management Review, Vol. 3, pp. 24-45. 
Cutler, D. M., Poterba, J. M. and Summers, L. H. (1989). 'What Moves Stock Prices?' Journal of Portfolio Management, Vol. 15, pp. 4-12.

DeLong, J. B., Shleifer, A., Summers, L. H. and Waldmann, R. J. (1990). 'Noise Trader Risk in Financial Markets', Journal of Political Economy, Vol. 98, pp. 703-738.

Diamond, D. W. and Verrecchia, R. E. (1981). 'Information Aggregation in a Noisy Rational Expectations Economy', Journal of Financial Economics, Vol. 9, pp. 221-235.

Dow, J. (1995). Arbitrage, Hedging and the Welfare Economics of Financial Innovation: A Model of Cross-Market Liquidity Effects. Working Paper, London Business School

Dow, J. and Gorton, G. (1994). Arbitrage Chains. Journal of Finance, 49, 819-849.

Dow, J. and Gorton, G. (1997). Noise Trading, Delegated Portfolio Management and Economic Welfare. Journal of Political Economy, 95, 1024-1050.

Dumas, B. (1992). Dynamic Equilibrium and the Real Exchange Rate in a Spatially Separated World. Review of Financial Studies, Vol. 5, pp. 153-180.

Dumas, B. (1994). Partial Equilibrium versus General Equilibrium Models of the International Capital Market. in Van Der Ploeg, F. (eds) The Handbook of International Macroeconomics. Blackwell, Oxford, 301-347.

Fama, E.F. and French, K.R. (1989), 'Business Conditions and Expected Returns on Stocks and Bonds', Journal of Financial Economics, Vol. 25, pp. 23-49.

Fama, E.F. and French, K.R. (1992), 'The Cross-Section of Expected Stock Returns', Journal of Finance, Vol. 47, pp. 427-465.

Fama, E.F. and French, K.R. (1993), "Common risk factors in the returns on stocks and bonds", Journal of Financial Economics, Vol. 33, pp. 3-56.

Ferson, W.E. and Harvey, C.R. (1991), 'The Variation of Economic Risk Premiums', Journal of Political Economy, Vol. 99, pp. 385-415.

Ferson, W.E. and Harvey, C.R. (1993), 'The Risk and Predictability of International Equity Returns', Review of Financial Studies, Vol. 6, pp. 527-566.

French, K.R., Schwert, G.S. and Stambaugh, R.F. (1987), 'Expected Stock Returns and Volatility', Journal of Financial Economics, Vol. 19, pp. 3-30.

Glosten, L.R., Jagannathan, R. and Runkle, D.E. (1993), 'On the Relation between the Expected Value and the Volatility of the Nominal Excess Return on Stocks', Journal of Finance, Vol. 48, pp. 1779-1801.

Granger, C.W.J. and Teräsvirta, T. (1993), Modelling Nonlinear Economic Relationships, Oxford: Oxford University Press. 
Haggan, V. and Ozaki, T. (1981), 'Modelling Non-Linear Random Vibrations using an Amplitude-Dependent Autoregressive Time Series Model, Biometrika, Vol. 68, pp. 189-196.

He, H. and Modest, D. (1995). 'Market Frictions and Consumption-Based Asset Pricing', Journal of Political Economy, Vol. 103, pp. 94-117.

Keim, D.B. and Stambaugh, R.F. (1986), 'Predicting Retums in the Stock and Bond Markets', Journal of Financial Economics, Vol. 17, pp. 357-390.

Krägler, H. and Krugler, P. (1993). Nonlinearities in Foreign Exchange Markets: A Different Perspective. Journal of International Money and Finance, 12, 195-208.

Kyle, A. S. (1985). Continuous Auctions and Insider Trading. Econometrica, 53, 1315-1335.

Leung, M. T., Daouk, H. and Chen, A-S. (2000), 'Forecasting Stock Indices: a Comparison of Classification and Level Estimation Models', International Journal of Forecasting, Vol. 16, pp. 173-190.

Martens, M., Kofman, P. and Vorst, T. C. F. (1998). A threshold Error Correction Model for Intraday Futures and Index Returns. Journal of Applied Econometrics, Vol. 13, pp. 245-263.

McMillan, D. G. (2001). 'Non-Linear Predictability of Stock Market Returns: Evidence from Non-Parametric and Threshold Models', International Review of Economics and Finance, Vol. 10, pp. 353-368.

Obstfeld, M. and Taylor, M.. (1997). Nonlinear Aspects of Goods-Market Arbitrage and Adjustment: Heckscher's Commodity Points Revisited. Journal of the Japanese and International Economies, Vol. 11, pp. 441-479.

Perez-Quiros, G and Timmermann, A (2000). Firm Size and Cyclical Variations in Stock Returns. Journal of Finance, Vol 55, pp. 1229-1262.

Pesaran, M H and Timmermann, A (1995). Predictability of Stock Returns: Robustness and Economic Significance. Journal of Finance, Vol 50, pp. 1201-1228.

Pesaran, M.H. and Timmermann, A. (2000), 'A Recursive Modelling Approach to Predicting UK Stock Returns’, Economic Journal, Vol. 110, pp. 159-191.

Poterba, J.M. and Summers, L.H. (1988), 'Mean Reversion in Stock Prices', Journal of Financial Economics, Vol. 22, pp. 27-59.

Ross, S. (1976). 'The Arbitrage Theory of Capital Markets', Journal of Economic Theory, Vol. 13, pp. 341-360.

Sercu, P., Uppal, R. and Van Hulle, C. (1995). The Exchange Rate in the Presence of Transactions Costs: Implications for Tests of Purchasing Power Parity. Journal of Finance, Vol. 50, pp. 1309-1319.

Shleifer, A. (2000). Inefficient Markets. An Introduction to Behavioural Finance. Clarendon 
Lectures in Economics, Oxford University Press: Oxford.

Shleifer, A. and Summers, L. H. (1990). 'The Noise Trader Approach to Finance', Journal of Economic Perspectives, Vol. 4, pp. 19-33.

Taylor, M. P. and H. Allen (1992). 'The Use of Technical Analysis in the Foreign Ex change Market', Journal of International Money and Finance, Vol. 11, pp. 304-314.

Teräsvirta, T. (1994), 'Specification, Estimation and Evaluation of Smooth Transition Autoregressive Models', Journal of the American Statistical Association', Vol. 89, pp. 208-218.

Teräsvirta, T. and Anderson, H.M. (1992), 'Characterising Nonlinearities in Business Cycles using Smooth Transition Autoregressive Models', Journal of Applied Econometrics, Vol. 7, pp. S119-S136. 
Figure 1. Transition Functions
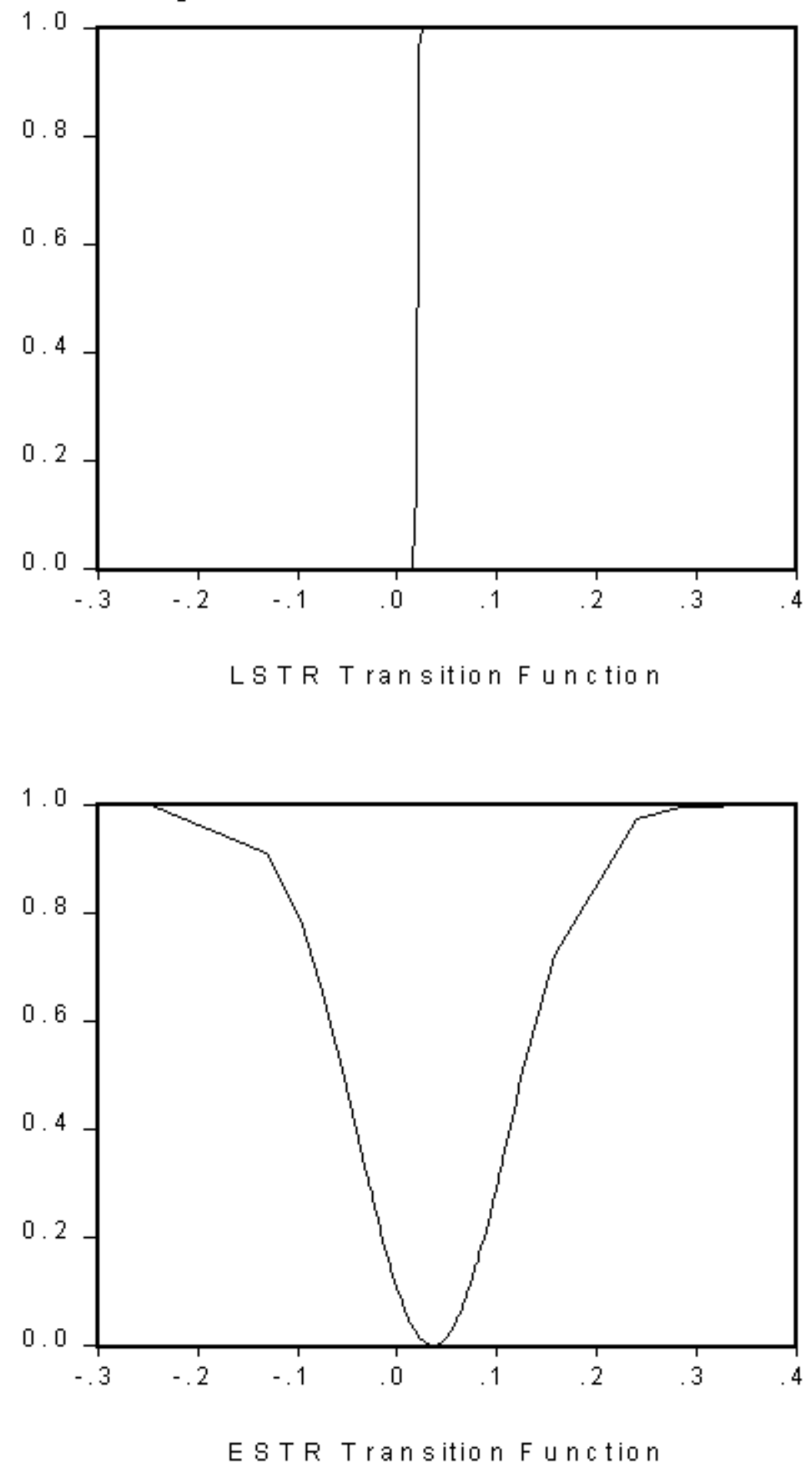
Notes:

1. The rationale generally offered for noise trading is that it allows privately informed traders to profitably exploit their informational advantage, without which market efficiency would not be assured (eg. Kyle, 1985). That rationale does not, however, explain the reasons for noise trading, on which there are differing views. Noise trading may be regarded as, either, rational agents trading for liquidity and hedging purposes, consistent with a fully rationalefficient-markets perspective (Diamond and Verrechia, 1981; Biasis and Hillion, 1994; Dow, 1995; Dow and Gorton, 1994, 1997), or, irrational (or not fully rational) agents trading on beliefs and sentiments that are not justified by news concerning underlying fundamentals (Black, 1986; Schleifer and Summers, 1990; De Long et. al., 1990). An interesting alternative interpretation recently offered by Dow and Gorton (1997) suggests that delegated portfolio managers may engage in noise trading in order to appease clients or managers who are unable to distinguish purposeful inaction from non-purposeful inaction, as a result of which the amount of noise trading can be large compared to the amount of hedging volume, and Pareto improving.

2. Taylor and Allen (1992) argue that non-linearities may account for the use of technical analysis amongst foreign market traders, arguing that if the structure of financial markets is inherently non-linear then fundamentalists, who base their analysis on linear forecasting models as approximations for price behaviour, may lose credibility while technical analysis, which by definition works closely with minute market movements, allows analysts to gain an intuitive feel for the market and develop a closer approximation to the underlying economic structure.

3. Shleifer justifies the assumption that arbitrageurs may be faced by short horizons on the basis that arbitrageurs typically do not manage their own moneybut are agents for investors who evaluate their performance at regular intervals and reward them accordingly. Mispricings that take longer to correct than the evaluation horizon may therefore reducearbitrageurs' remuneration. Further, many arbitrageurs borrow money and securities from intermediaries to put on their trades and, whilst they have to pay interest, they also face the risk of liquidation by lenders if prices move against them and the value of collateral falls.

6. An alternative ESTAR motivation is provided by consideration of market depth, whereby the process by which the market can clear reasonable quantities of stock at market prices may differ from the process required to trade large quantities of stock outside the range of price necessary to clear the market. Moreover, whether a large range of trades can be represented by the same process, in which case the market may be said to be 'deep', or whether, the market is characterised by limited depth, in which case the middle regime of the ESTR model may be narrow.

7. The optimisation problem in non-linear least squares is conditional on the starting values and consists of finding the minimum of the criterion function:

$$
Q_{T}(\alpha)=\sum_{t=1}^{T}\left\{x_{t}-g\left(\alpha, \Psi_{t-1}\right)\right\}^{2}
$$

with respect to , the parameter vector (see Klimko and Nelson (1978) for the conditions for consistent estimation).

8. The financial and macroeconomic series chosen are those to have been previously reported as being important, see the papers referred to in the Introduction.

9. Unit root test results are suppressed for space consideration, but available upon request from the author. 
10. Whilst the lag length decision is obviously data led the selection of low lag orders perhaps has some intuitive economic appeal. Specifically, changes in interest rates which affect the discount rate and portfolio selection between equity and fixed income asset have an immediate effect, while factors which affect the dividend process take longer due to slower information release and smoothing behaviour.

11. The BDS (Brock, Dechert, Sheinkman and LeBaron, 1996) statistic tests the null that the series in question are iid against an unspecified alternative using a non-parametric technique, and has power against a variety of non-linear processes (Brock, Hsieh and LeBaron, 1991). More formally, the test statistic is based upon a measure of spatial correlation in $m$-dimensional space known as the 'correlation integral' (Grassberger and Procaccia, 1983) and is defined as:

$$
W_{m, T}(d)=T^{0.5}\left[C_{m, T}(d)-C_{1, T}(d)^{m}\right] / \sigma_{m, T}(d)
$$

where is the sample standard deviation of the data, and $C_{m, T}(k)$ the sample correlation integral given 'embedding dimension', $m$, and distance, $d$. In applications to ii series the BDS statistic is asymptotically distributed as a standard normal, $W \sim N(0,1)$. 